\title{
Polylogical Core of Modern Intercultural Interaction Models
}

\section{| Astafyeva Olga Nikolaevna ${ }^{1}$ | Belyakova Irina Gennadievna ${ }^{2}$ |}

\author{
${ }^{1}$ Doctor of Philosophical \\ Sciences, Professor, Russian \\ Presidential Academy of \\ National Economy and Public \\ Administration, Moscow, \\ Russian Federation \\ ${ }^{2}$ Doctor of Culturology, \\ Associate Professor, Russian \\ Presidential Academy of \\ National Economy and Public \\ Administration, Moscow, \\ Russian Federation \\ 1on.astafyeva@igsu.ru/ \\ 2ig.belyakova@igsu.ru
}

\begin{abstract}
The article is devoted to the problems of transformation and phenomenon of complication of intercultural communication models. The significance of the study lies in the fact that intercultural communication through the prism of cultural and civilizational developments reflects the sociocultural changes taking place at all levels of social development. The problem of application of theoretical knowledge about the communicative paradigm of modern culture with its polylogical core for the development of a specific model of intercultural communication and effective cultural policy relates to the difficulties of achieving compliance of the research results with the real state of the sociocultural environment. Basing on the previous and current research approaches and taking into consideration a systemic and synergistic approach as well as a dialogue concept, the authors aim to investigate theoretical modeling of intercultural interaction. As a result of investigation, the authors conclude that the study of models of intercultural interaction cannot be carried out without understanding the principles and factors of the dynamics of cultural changes in the modern world which allows us to consider the transition from a dialogue model to a polylogue model as a natural stage in the dynamics of culture. Also, the methodological set of philosophical and cultural studies of the dynamics of modern culture is proved as constantly expanding due to the new tendencies, like total digitalization. It is stated that overcoming outdated models of intercultural interaction and adopting the new ones is a long process that must be tested by the human society. KEYWORDS

culture; intercultural interaction; polylogical model; cultural policy; intercultural dialogue
\end{abstract}

\section{INTRODUCTION}

The intercultural communication in the modern context of cultural and civilizational changes reflects the sociocultural transformations taking place at all levels of social development. Under the conditions of rapidly increasing information flows, it is dynamic, multifunctional, and simulated. The growing problems of misunderstanding and opposition at the interpersonal, intergroup, and inter-civilization levels require understanding and development of certain rules of intercultural communication in the era of globalism.

Overcoming old stereotypes, introducing tolerance into the social sphere, clarifying the self-identification of all strata of any society, especially multinational in composition, is impossible without intercultural communication as a social mechanism for overcoming the contradictions between global and local aspects of human activity in the modern world (Belyakova, 2017). 
The study of intercultural communication in the new conditions provides a theoretical substantiation, analysis, and determination of optimal ways of finding mutual understanding and interaction of all members of the global world, the formation of new models of intercultural communication in the context of the dialogue of cultures (Belyakova, 2016).

Their diversity of existing communication models that has been widely discussed by different scholars is explained by the principle of multiple description of systems and the dynamic nature of communication processes, where each model is created for the sake of a definite goal, which scientists set for themselves. Thus, putting the emphasis on achieving a complex cultural integrity within the framework of the holistic methodology I.A. Gerasimova reveals the unity of the plural in philosophical, cultural and religious concepts (Gerasimova, 2010).

\section{RESEARCH METHODS}

The basic methodology of our research is a systemic and synergistic approach, a dialogue concept. The object of this research is modern models of interaction of cultures, the subject is a complicated dialogue model of the polylogue of cultures. The purpose of the study is to substantiate the poly-generation of modern culture because of expanding the value foundations for understanding the diversity of cultures and the inclusion of new forms and types of social interaction in the context of the complication of the communication system in the information society in the era of digitalization. Openness to interaction and perspective changes in the modern world allows us to consider the transition from a dialogue model to a polylogue model as a natural stage in the dynamics of culture. At the same time, a polylogue, as a form of co-existence together, predetermines the creation of a situation of co-creation of meanings and deep interpretation, since the plurality and poly variety of cultural texts is generated by people interacting with them - carriers of different cultural values and worldviews.

To the scientific novelty of this article, we refer to the principle of the polylogue of cultures, which we consider as a sophisticated variety of a dialogical communication model that incorporates many cultures of the present, allowing for echoes with the cultures of the past and emerging cultures of the future. We believe that with this approach, the intersection of values and meanings, cultural worlds of many different cultures and subcultures that have rights or only become as such, are not leveled either by the globalization context or by cultural politicians in different countries, although they experience a certain influence. In our opinion, the concept of "polylogue of cultures" adequately conveys the "dialogue of many" as "many other" cultures, which corresponds to the main vector of human development - the preservation of cultural diversity and support for intercultural interaction.

\section{RESULTS AND DISCUSSION}

Theoretical modeling of intercultural interaction is a technology in demand in practice. The problem of adequate application of theoretical knowledge about the communicative paradigm of modern culture with its polylogical core for the development of a specific model of cultural policy is associated with the difficulties of achieving compliance of the diagnostic results with the real state of the sociocultural environment, with the search for a methodological substantiation of the existing discrepancies (differentiations) between theory and empirical reality. The existing interdependencies between the means of proof and interpretation in the process of modeling, difficulties and limitations of formalization are associated with the complexity of the phenomenon of culture, the main characteristics of which are freedom and creativity, powerful potential for self-development. It does not follow from this those socio-cultural processes, including intercultural communications, exclude 
managerial influences, and that programming the harmonization of the interaction of cultures is ineffective.

The proposed system of methodological principles and criteria, which makes it possible to develop several communication models, allows solving the most complex problems of socio-cultural development by including them in the strategic toolkit of cultural policy. Modeling in this case acts as a procedure for anticipating possible changes and forecasting the development of the situation in the field of intercultural interaction. An analysis of the communication models proposed by different authors makes it possible to concretize and refine the forecast (Nazarchuk, 2009). As emphasized, the procedure for the study of intercultural communications is a constantly renewed act of cognition and humanitarian expertise, without which the creation of cultural policy strategies for the medium and long term is difficult in principle. Considering that the process of globalization and trans nationalization of culture is accompanied by the development of infrastructure and the renewal of communication institutions that ensure the dynamics and density of cultural flows in the modern world, the scientific problems of developing models of intercultural interaction are becoming more and more relevant. But the main idea in substantiating our methodological approach is the idea embedded in the hypothesis of understanding intercultural communication as a powerful factor ("stimulator") in the transformation of value and semantic space. Prospects for understanding another culture are associated not only with adequate understanding and accuracy of interpretation, but also with the ability of the scientific and expert community to propose new rules for interaction, technologies for assessing the effectiveness of existing norms. Of course, this is an indicator of a society's ability to create a culture of communication that responds to social change.

In scientific and theoretical works, intercultural dialogue as a process is considered in the context of the genesis of the communicative paradigm, where the very concept of dialogue undergoes evolution, while maintaining the function of its "core". As a result, the principles of universal dialogue, while remaining substantively relevant in modern culture, act as a semantic integrator of a complicated polylogical matrix. And although it can be considered that the concept of "dialogue" with this approach is partially overlapped by the concept of "polylogue", nevertheless it is fundamentally important not to consider the polylogue as a simple summation of the participants in communication.

The appeal to this concept is dictated by certain methodological goals, first - to show the possibility of researching new forms of interaction of cultures that form a complex polygeneration of modern culture. The communicative approach, based on the idea of dialogue, allows, based on the values of "one's" culture, to highlight the uniqueness of each of them in the space of interaction with "other" cultures, to understand the complex value-semantic interweaving of many independent counterpoint lines and to find common, close, thanks to which is what forms a special configuration of modern culture- the very "unity of diversity."

The appeal to the concept of dialogue is reasonable but does not fully reveal the complexity of the phenomenon when it comes to the interaction of many cultures, in which the built dialogicity forms complex value-semantic interweaving, due to their interpretation and complementarities. In this case, we mean not only ethno-cultural diversity within the framework of a specific national culture, but the matrices of modern culture (in the country and spatial-territorial dimensions, first of all), where the classical (professional), mass , folk culture, transforming both the common space - a model of unity, and each of the cultures that make up this unity, leading to the emergence of "hybrid" forms at local levels of interaction.

In this situation, the appeal of researchers to the concept of "polylogue" seems to us more appropriate. The concept of "polylogue" conveys the emerging complex, filled with 
counterpoint connections of lines, the space of culture (it is this that is sometimes suggested to be called post-postmodern culture). It is formed by cultures included in the dialogue context of interaction, which do not lose their independence, but change the principles of interaction (for example, when classical art is introduced into performance formats, in theatrical art, in the immersive form of theatrical performances, etc.)

Thus, the polylogue of cultures is a complicated dialogue form of interaction of many cultures and a characteristic feature of the cultural space is poly-subjectness, which testifies to the scale of the spread of polylogical principles, their content potential for the development of a theoretical model. The intersection of values and meanings of a multitude of cultural worlds that have equal rights (or seek to acquire their right) form the polygeneration of modern culture.

We consider it advisable to remind that, based on the synergetic concept of culture, the integrity of culture is always an evolving "multiple integrity", in its "complexity" it is one of the basic characteristics of culture as a system that allows it to convey its inherent internal variety of forms and styles, patterns and meanings. With this approach, unification and focus on simplification are considered as signs of degradation of culture, contributing to its entropy, as an anthropo-socio-cultural system (Astafyeva, 2006, 2019).

Accordingly, the achievement of integrity in the polylogical fabric of a cultural environment that develops nonlinearly, absorbing the meanings of different cultures, is not possible outside the general focus on reducing instability and instability associated with reconciling the continuity of traditions and the need for innovation, with achieving harmony between the creative essence of culture and its direction for cumulation; that is, an orientation towards both conservation and development.

One of the models of modern culture with a polylog core is a special type of network culture, which has the following features: development according to the principle of selforganization; complex internal interactions, decentralization and expansion of horizontal ties, weakening of hierarchy, transnationality; orientation towards the openness of information and communication links (intermedia and interactivity) and collaboration; extreme aggravation of the situation to maintain the environment in a state of creativity; pluralism, diversity, etc.

The types and forms of interaction of cultures in the context of the polylogical paradigm in the system of social management, in particular the models of cultural policy, where they are considered as:

- a special type of relations and connections that develop between cultures, as well as those influences and mutual changes that manifest themselves in the course of these relations, which determine the mechanisms of managerial influences on socio-cultural processes in society;

- the basic principle of the functioning of cultures in the context of globalization, which makes it possible to redistribute the forms and methods of supporting cultural diversity;

- a consequence of integration processes in culture, transforming the communication system.

Thus, in order to overcome the multidirectional dynamics of modern culture, the considered principles, laid down in the strategy of cultural policy of different countries, are consistent with the principles of the concept of sustainable development. Culture is seen as the key to sustainable development, and dialogue and polylogue, as a requirement of the time, are cultural imperatives (Astafyeva, 2019).

Let us emphasize that the decisive importance in the processes of polylogical interaction of cultures is acquiring a change in the states, qualities, areas of activity, values of a 
particular culture, the generation of new forms of cultural activity, spiritual guidelines, and signs of people's way of life under the influence of impulses coming from outside. The growth of the dynamics of cultural change is associated with the formation of global infrastructures that facilitate the penetration of samples and styles across national borders, the development of creative industries that transform cultural flows, and the emergence of transnational corporations and associations for the production, distribution and distribution of cultural goods and services.

The key sectors providing the density of cultural ties are the mass media, the Internet and tourism, which largely confirms the information and communication dominant of the modern era. This leads to the emergence of a global culture, which is formed in the process of active interaction and mutual influence of national cultures, actualizing the need for the general, intersubjective. Further, in the process of trans nationalization of the cultural space, the risks of unification and expansion, the loss of identity are increasing, which leads to the complication of polylogical communications due to ultra-fast updates of information technologies (Astafyeva, 2007).

Thus, the researchers' appeal to the concept of polylogue in the above-described understanding makes it possible to expand existing models of intercultural interactions in a complex world and thus, avoid semantic and conceptual "substitutions", get involved in interdisciplinary discourse and take into account the principles of polylogical thinking.

\section{CONCLUSION}

1. Openness to interaction and perspective changes in the modern world allows us to consider the transition from a dialogue model to a polylogue model as a natural stage in the dynamics of culture. At the same time, a polylogue, as a form of co-existence together, predetermines the creation of a situation of co-creation of meanings and deep interpretation, since the plurality and poly variety of cultural texts is generated by people interacting with them - carriers of different cultural values and worldviews.

2. The methodological palette of philosophical and cultural studies of the dynamics of modern culture is expanding. The comprehension of the polylogical model of interaction concretizes the tasks of researchers who must see the specificity of each culture in a complex counterpoint fusion and comprehend its features, clearly define the prospects for self-expression in a globalizing world.

3. Since the polylogue reflects the essence of the "information society" with the network logic of its basic structure, the procedure for understanding, evaluating, and interpreting conceptual ideas and discourses becomes more complicated. The open expression of the expert opinion of scientists becomes a procedure for co-creation and the discovery of new rules and norms, the formation of a new hierarchy of values and the birth of meanings. Accordingly, the types of research, management, educational and other technologies and approaches also need constant updating. The study of models of intercultural interaction cannot be carried out without understanding the principles and factors of the dynamics of cultural changes, as well as considering the integration of the communication process into a specific space-time frame. Hence, attention is paid not only to the subjects of communication and the space of culture, but also to the temporality of the processes of intercultural communication in the context of digitalization.

4. The "mosaic" configuration of modern culture with its postmodern eclecticism is gradually changing into a "puzzle" configuration permeated with the inner meaning of unification, enhanced by the dynamics of communications, and understanding of the interdependence of cultures - traditional and current, mass and transnational, "selfaligning" into a complete picture. 
5. Concluding our study, we emphasize that overcoming outdated models of interaction is a long process that must be tested by society: a particular model must be recognized not as an exclusively private practice acceptable for one situation but perceived by other members of the community as a "response" to "challenges "from other members of society, i.e., get approval for meeting expectations with model correction capabilities and implementation technologies focused on achieving the integrity of modern culture.

\section{REFERENCES}

Astafyeva O.N. (2019). Sustainable development strategy in the cultural policy of Russian regions // World of Russian-speaking countries = 俄语 国家 评论 $=$ World of Russianspeaking countries. scientific journal. - Yaroslavl: RIO YAGPU, No. 1. pp. 43-51.

Astafyeva O. N. (2019). The polylogue of cultures as an extension of the dialogical paradigm in the context of globalization // Information era: new paradigms of culture and education: a collective monograph / ON. Astafieva, L.B. Zubanova and others, executive editor N.B. Kirillova. - Yekaterinburg: Publishing House of the Ural University. pp.78 - 101;

Astafyeva O.N. (2006). Polylogue in the context of trans nationalization of cultural space: the new reality of the globalizing world, Theory and practice of culture. Almanac. Issue 4. M., pp. 6-18;

Astafyeva O. N. (2007). Trans nationalization of Cultural Space: State and Problems of Coordination of Communication Strategies Man, Culture and Society in the Context of Globalization. M. S. 5-11.

Belyakova I.G. (2016). Intercultural communication and multiculturalism. Transnational competence in the era of globalization. "Society: philosophy, history and culture" No. 3, - pp. 64-66.

Belyakova I.G. (2017). Modern intercultural communication: dynamics of global transformations. Monograph M: Sputni. -- 215p.

Gerasimova I.A. (2010). The unity of the plural (epistemological analysis of cultural practices). - M .: Alfa-M. .-- 304 p.

Nazarchuk A.V. Theory of communication in modern philosophy / A.V. Nazarchuk. M. 